Running head: DEVELOPMENT OF COGNITIVE FLEXIBILITY

Cognitive Flexibility In Young Children: A General or Task-Specific Capacity?

\author{
Gedeon O. Deák ${ }^{1}$ and Melody Wiseheart ${ }^{2}$ \\ ${ }^{1}$ University of California, San Diego, United States \\ ${ }^{2}$ York University, Ontario, Canada
}

Corresponding Author:

Gedeon O. Deák

Department of Cognitive Science

University of California, San Diego

9500 Gilman Dr.

San Diego, CA 92093-0515

gdeak@ucsd.edu

(858) 822-3352

Word Count: 9,631 


\begin{abstract}
Cognitive flexibility is the ability to adapt to changing tasks or problems. To test whether cognitive flexibility is a coherent cognitive capacity in young children, we tested 3- to 5-yearolds' performance on two forms of task switching: rule-based (Three Dimension-Changes Card Sort; 3DCCS) and inductive (Flexible Induction of Meaning-Animates and Objects; FIM-Ob and FIM-An), as well as tests of response speed, verbal working memory, inhibition, and reasoning. Results suggest that cognitive flexibility is not a globally coherent trait: only the two inductive word-meaning (FIM) tests showed high inter-test coherence. Task- and knowledgespecific factors also determine children's flexibility in a given test. Response speed, vocabulary size, and higher-order causal reasoning skills further predicted individual and age differences in flexibility, although they did not have the same predictive strength for all three flexibility tests.
\end{abstract}

Keywords: causal reasoning; cognitive flexibility; executive functions; fluid intelligence; individual differences; inhibition; rule switching; vocabulary; word learning; working memory 


\section{Cognitive Flexibility In Young Children: A General or Task-Specific Capacity?}

Cognitive flexibility is the capacity to modify working memory, attention, and response selection in response to changing endogenous and exogenous task demands. Cognitive flexibility has been the focus of behavioral and neuropsychological studies (e.g., Eslinger \& Grattan, 1993; Kramer, Cepeda \& Cepeda, 2001; Smith \& Blankenship, 1991) using a variety of tasks and contexts, and wide age ranges (Ionescu, 2012). Age-related changes in cognitive flexibility have been reported in tests of rule-switching (Zelazo, Frye \& Rapus, 1996), word learning (Deák, 2003), spatial reasoning (Hermer-Vazquez, Moffet \& Munkholm, 2001), categorization (Blaye \& Bonthoux, 2001), and problem solving (Chen, 1999). Many studies and paradigms suggest that flexibility improves significantly from 3 to 6 years of age. If flexibility develops similarly across multiple tasks, it might mean that flexibility is a generalized cognitive capacity: an 'executive' control process that operates over a wide range of task contexts (e.g., Martin \& Rubin, 1995; Zelazo \& Frye, 1998).

The idea of general cognitive capacities has a long history in psychology (e.g., Ackerman, 1988; Engle \& Kane, 2004; Humphreys, 1979). Many researchers have argued that a few general executive functions (EFs) control cognition in a variety of tasks and contexts (but see Barkley, 2012; Jurado \& Roselli, 2007). Many proposed EF frameworks incorporate a function of cognitive flexibility or 'set shifting' (e.g., Miyake, Friedman, Emerson, Witzki, Howerter, \& Wager, 2000). A related hypothesis is that EFs are stable, endogenous traits of individuals (Friedman, Miyake, Young, DeFries, Corley, \& Hewitt, 2008). This implies that individual differences in cognitive flexibility should be constant across tasks, times, and content. Some authors have suggested that these general EFs, including flexibility, mature and stabilize in early childhood (Carlson, Moses \& Breton, 2002; Davidson, Amso, Anderson, \& Diamond, 2006). 
That hypothesis is not uncontroversial: an alternative is that flexibility develops in a domain-specific fashion, as children gain task-specific skills and knowledge (Luwel, Verschaffel, Onghena, \& De Corte, 2003; Ravizza \& Carter, 2008). By this view, flexibility might improve in many tasks between 3 and 5 years simply because children acquire a great deal of varied knowledge and skills during that time. That is, flexibility might improve across tests due to parallel gains in knowledge and skills across domains, not development of a generalized EF. If this is true, we should see older children's flexibility relating to individual domain-specific skills. Relatedly, school-aged children's flexibility in reading-related tasks is partly predicted by their reading skill (Cartwright, Marshall, Dandy \& Isaac, 2010).

It is also possibility that children's flexibility is determined by both a general EF and task- or domain-specific skills and knowledge. Another possibility is that there are several dissociable, moderately general flexibility capacities, and each is more relevant to (or more heavily recruited for) some tasks more than others (Kim, Johnson, Cilles \& Gold, 2011). Both of these alternatives would predict limited between-test intra-individual coherence of flexibility.

Determining whether children's cognitive flexibility depends on general capacities, on task-specific knowledge and skills, or both, would explain developmental changes in cognitive control. However, there is little evidence on the coherence of children's flexibility. Most studies implicitly treat flexibility as a general capacity that can be assessed by a single rule-switching test, despite the fact that external and construct validity of most tests are not established.

To address this question, we gave preschool children three tests of flexibility, representing two types of cognitive skills or domains. If individual children's flexibility is similar across all tests, it will imply a general capacity. If it is consistent only between two tests from the same task domain, it will suggest that flexibility is determined by task-specific skills, or 
by several moderately-specific capacities, or both. If flexibility is inconsistent across all three tests, it will suggest that flexibility is largely determined by task-specific knowledge.

Selecting comparable tests with different content domains and task demands is challenging because most studies of young children use one test: the Dimensional Change Card Sorting test or DCCS (Zelazo, 2006). This is a rule-switching test: children learn two deductive, binary rules for sorting two stimuli. They are told to follow one rule and, at some later time, to switch to the other rule. The test yields robust age differences: most 3-year-olds fail to follow an instruction to switch to the second rule, but most 5-year-olds correctly switch. The test classifies each child as flexible or inflexible, with little further differentiation. Although recent studies have explored more sensitive measures of rule-switching efficiency in older children (e.g., Cepeda et al, 2001), these paradigms are not well suited for preschool children.

Other researchers have, however, tested preschooler in age-appropriate tests that yield parametric estimates of flexibility. These tests involve more sub-tasks and switches, plus more trials and response options, than typical tests (Deák \& Narasimham, 2003, 2013; Narasimham, Deák, \& Wiseheart, in revision). Notably, the tests also represent a different type of task: cueinduction rather than rule-switching. Cue-induction is the common process of selecting and integrating multiple sources of information that are probabilistically related to some task or judgment; thus the judgment is inductive (i.e., indeterminate). Cue-induction flexibility is needed for making different inferences based on different subsets of available information, or cues.

Cue-induction tests of flexibility are useful because rule-switching tests might not capture young children's common everyday cognitive activities. Rule-switching tests demand arbitrary reversals of symbolic mappings, which play a small role in preschoolers' everyday experience (Deák, 2003; see also Burgess, Alderman et al, 2006). These reversals are analogous to solving 
an algebra problem with premises 'Let $\mathrm{X}=4$ and $\mathrm{Y}=3$,' then getting another problem with the (switched) premises, 'Let $\mathrm{X}=3$ and $\mathrm{Y}=4$.' Such arbitrary mapping-reversals are an unusual sort of symbol manipulation - in fact, they are confusing for adolescents learning algebra (Knuth, Alibali, McNeil, Weinberg, \& Stephens, 2011). If they are unfamiliar to preschoolers, then ruleswitching tests might be assessing a fairly peculiar skill, not one that generalizes to everyday tasks that require flexibility. This might explain why brief feedback or practice can eliminate preschoolers' switching errors (Bohlmann \& Fenson, 2005; Perner \& Lang, 2002). It can also explain why rule switching improves from 3 to 5 years, when many children start attending preschool classes that impose an expanding, increasingly elaborate schedule of rules.

If cognitive flexibility reflects task-specific skills rather than a generalized EF, then ruleswitching might be an acquired skill: a learned ability to process, adopt, and reverse arbitrary rule-to-response mappings. However, many everyday situations instead children to shift attention and modify behavior in response to social or linguistic cues that are probabilistically associated with the prevailing task context. These social and linguistic cues seldom reverse or change arbitrarily; rather, new cues are usually related to some social event (e.g., topic shift, new interlocutor, or new information). Also, the cues are seldom explicitly stated or explained. Thus, everyday flexible cue-induction requires sensitivity to changeable, probabilistic, implicit, and pragmatically constrained contextual information.

Preschool children can flexibly use such cues to make inductive judgments (e.g., Nguyen $\&$ Murphy, 2003). For example, between 3 and 5 years, children become more flexible at using changing semantic cues to infer novel word meanings (Deák, 2000, 2003; Deák \& Narasimham, 2003, 2013). When told that an object is "made of molap," most preschoolers infer that molap refers to its material. Later, wehn told that the same object "has a fodi," most of the children will 
infer that fodi refers to a salient part, not material. These inferences require children to constrain the possible meanings of successive words according to each one's specific semantic context. This paradigm encapsulates a pervasive demand of children language learning: flexible use of implicit available cues to interpret the novel words they frequently hear.

Cue-induction flexibility improves from 3 to 5 years, parallel to improvement in ruleswitching flexibility. This parallel development might suggest a generalized capacity for flexibility. Alternately, it might be circumstantial, since most cognitive tests show improvement from 3 to 5 years. Suggestively, there is evidence that cue-induction and rule-switching flexibility rely on distinct neural substrates. Studies of adult humans and rats suggest a partial dissociation between hippocampal mechanisms for learning specific, well-defined contingencies (i.e., rules), and striatal mechanisms for learning probabilistic cue-outcome associations (Frank, O'Reilly \& Curran, 2006; O'Reilly \& Frank, 2006). The former might contribute more to ruleswitching flexibility, and the latter to cue-induction flexibility (Thompson-Schill, Ramscar \& Evangelia, 2009). Both develop in early childhood (Ramscar, Dye, Gustafson, \& Klein, 2013), but no study has directly compared children's rule-switching and cue-induction flexibility.

One issue to consider in comparing flexibility across tests is sub-task difficulty-that is, the difficulty (based on discriminability, specificity, etc.) of specific cues for each problem-type within a test. Children's ability to comprehend and utilize a particular cue or rule will affect their performance on specific questions or sub-tasks, and their overall flexibility on the test. Errors (e.g., perseverating on a rule) might be due not to general inflexibility but to poor comprehension of a cue or rule. For example, 3-year-olds' comprehension of words in the DCCS (e.g., "color"; "shape") predicts whether they perseverate (Munakata \& Yerys, 2001). Also, the strength of preschoolers' working memory representation of rules determines their rule-switching speed, 
even when they do not make errors (Holt \& Deák, 2014). Children's conceptual knowledge also affects how readily they switch between sub-tasks (Blaye, Bernard-Peyron, Paour \& Bonthoux; 2006; Deák, Ray \& Pick, 2004). Thus, specific knowledge affects flexibility, and it is important to control or assess the specific difficulty of each (cue- or rule-based) sub-task, and of each overall test, in order to interpret similarities and differences between tests.

To minimize this problem, we applied several strategies in our design: First, tests were designed to be similar in difficulty, so differences in flexibility would not be entirely due to between-test differences in sub-task difficulty. However, it can be challenging to equate cue or rule difficulty across tests for young children. Thus, a second strategy is that sub-tasks within each test were sequenced similarly, starting with the easiest cue/rule first, then the next harder cue/rule, and finally the hardest cue/rule. This is necessary because sub-task order can affect flexibility (e.g., Deák et al, 2004; Ellefson, Shapiro, \& Chater, 2006). If order effects were inconsistent across tests, it would complicate or invalidate between-test comparisons. Third, we assessed flexibility in each test using a measure that partly corrects for differences in sub-task difficulty: [Correct-Switches] $\div$ [Opportunities-to-Switch], or CORSWOPS (see below). Fourth, in some analyses each child's accuracy on the first cue/rule of each flexibility test was treated as a covariate. This separates some variance due to task-related cue/rule comprehension. Finally, children completed tests of conceptual and linguistic knowledge (e.g., receptive language; see below) to determine whether these factors predicted test-by-test variability in flexibility.

The last strategy relates to a secondary goal of this investigation: to determine whether flexibility (rule-switching, cue-inductive, or both) relates to children's executive functions (EF). Many EFs change greatly from 3 to 5 years while cognitive flexibility is developing. Perhaps changes in EFs contribute to changes in flexibility (Davidson, Amso, Anderson, \& Diamond, 
2006; Thompson et al, 2009). Miyake et al (2000) argued that flexibility is distinct from, but related to, other EFs including working memory and cognitive inhibition. Children's flexibility might be also related to EFs, it has been suggested: either to cognitive inhibition (Zelazo, Müller, Frye, \& Marcovitch, 2003), or inhibition and working memory (e.g., Carlson, 2005), or to processing speed (Cepeda et al, 2000). Currently the relation remains unclear. Most previous studies have tested only rule-switching flexibility, so the relation of EFs to cue-induction as well as rule-switching flexibility has not been explored. However, two studies found no reliable relation between cue-induction flexibility and verbal inhibition (Deák \& Narasimham, 2003, 2013). The current study examined relations between both types of flexibility and three EFs: working memory, inhibition, and processing speed.

In sum, we investigated three main questions: First, whether there is a generalized capacity for flexibility, as indicated by within-child consistency between rule-switching and cueinductive tests. A finding of consistency between two tests of the same type (i.e., cue-induction flexibility), but not with one of another type (e.g., rule-following) would suggest distinct taskrelated flexibility mechanisms, but no global capacity. Second, we investigated whether shared variance in flexibility could be attributable to linguistic and conceptual knowledge. If flexibility is predicted by receptive vocabulary, for example, it would imply that cue comprehension mediates cognitive flexibility. Third, we investigated whether three EFs - working memory, inhibition, and processing speed—predict children's flexibility across tests.

To assess flexibility, 3- and 4-year-olds completed a test of rule-following flexibility and two tests of cue-inductive (word-meaning) flexibility. ${ }^{1}$ All tests provided parametric and nonparametric measures of flexibility because, unlike binary 2-alternative forced-choice tests (e.g.,

\footnotetext{
${ }^{1}$ Ideally children would have completed two tests of each type; however, only one test of rule-following flexibility was available that yields parametric estimates of flexibility in children as young as 3 years old.
} 
DCCS), each test switched between three rules or cues, with larger sets of more complex stimuli, and more response options. These features provide more test sensitivity and more differentiated responses (e.g., both perseverative and haphazard errors; see Barceló \& Knight, 2002).

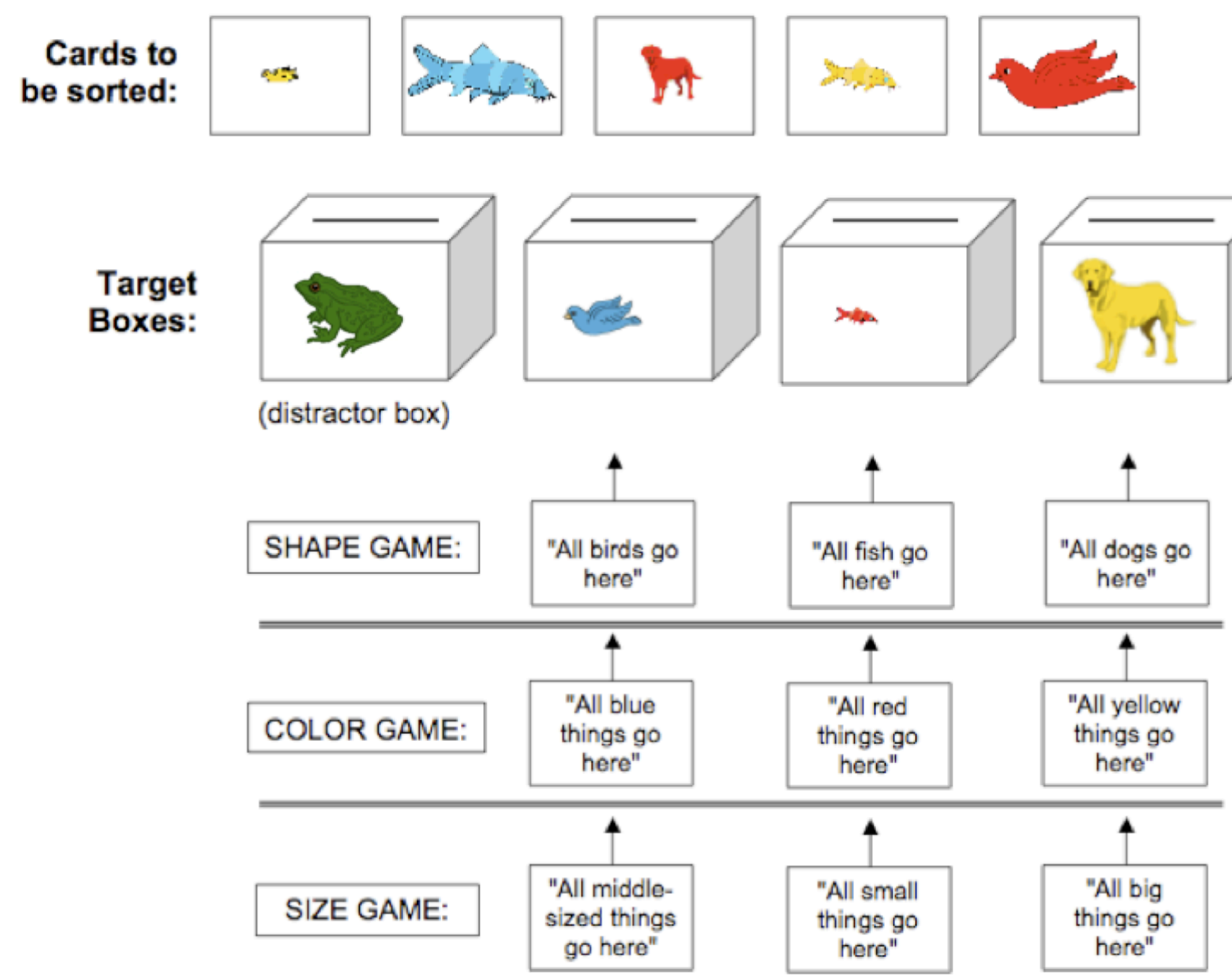

Figure 1. Sample 3DCCS stimuli. Test cards (to be sorted) varied in shape (i.e., animal), color, and size; each card could be sorted in a different box with a distinct target card, depending on the current rule (i.e., game): 'shape game', 'color game', or 'size game'.

The rule-switching Three Dimension-Changes Card Sorting (3DCCS) test used three sorting rules (size, color and shape) and two rule-switches (Deák, 2003; Cepeda \& Munakata, 2007). This requires more complex stimuli than the DCCS. Children sorted six test cards with four different values for each of three properties, as in Figure 1. There were four possible sorting responses (boxes) per trial. The test can yield both perseveration and haphazard-switching errors. 
However, overall flexibility in the 3DCCS is strongly correlated with flexibility in the DCCS (Narasimham et al., in revision), indicating convergent validity between the tests.

Children's cue-induction flexibility was measured in two FIM (Flexible Induction of Meaning) tests. The FIM-Objects test (Deák, 2000) presents words for object properties. Children hear three novel words for the same novel objects (see Figure 2). Each word can refer to one of three properties: shape, material, or a part. The three words for each Standard object follow three different phrase cues: 'is made of', 'is shaped like a(n)', and 'has a(n).' Children must infer each word's referent property, and identify another object with that property. Because the cue and word changes on each trial with a given set, children should generalize each word to a different property.
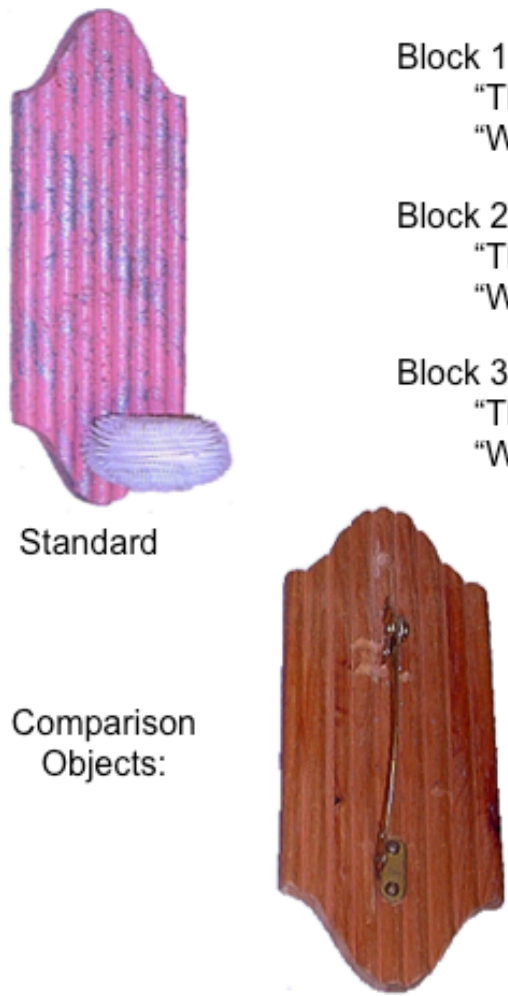

Block 1 ("is made of" cue), trial $n$ :

"This one is made of turob"

"Which of these other ones is also made of turob?"

Block 2 ("is shaped like" cue), trial $n+5$ :

"This one is shaped like an inrom"

"Which of these other ones is also shaped like an inrom?"

Block 3 ("has a" cue), trial $n+10$ :

"This one has a fodi"

"Which of these other ones also has a fodi?"

Figure 2. One of five FIM-Objects test sets, with example prompts from three trials. Top left object = Standard; comparison objects (bottom) from left: same-shape, same-material, same-part, distracter. Blocks include five trials, one per set, with the same cue. In the example, turob would generalize to the object second from left, inrom to the left-most object, and fodi to the object second from right. 
The FIM-Ob reveals robust age and individual differences in flexible use of cues for word learning (Deák, 2000, 2003). Few 3-year-olds flexibly use phrase cues to infer different meanings, whereas most 4-year-olds and almost all 5-year-olds do so. Variability across this age range is comparable to the 3DCCS. This will allows us to assess between-test similarities in individual flexibility. Any similarities can be 'triangulated' by comparing each test to a third test.

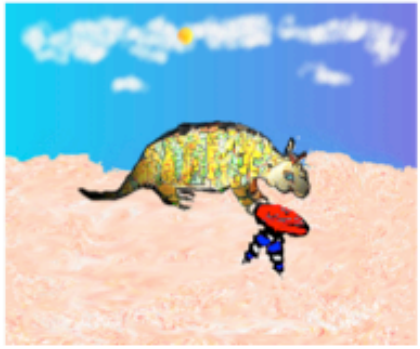

Standard
Block 1 ("is a" cue), trial $n$ :

"This one is a finnet"

"Which of these other ones also is a finnet?"

Block 2 ("holds a" cue), trial $n+5$ :

"This one holds an eland"

"Which of these other ones also holds an eland?"

Block 3 ("lives in a" cue), trial $n+10$ :

"This one lives in a toma"

"Which of these other ones also lives in a toma?"
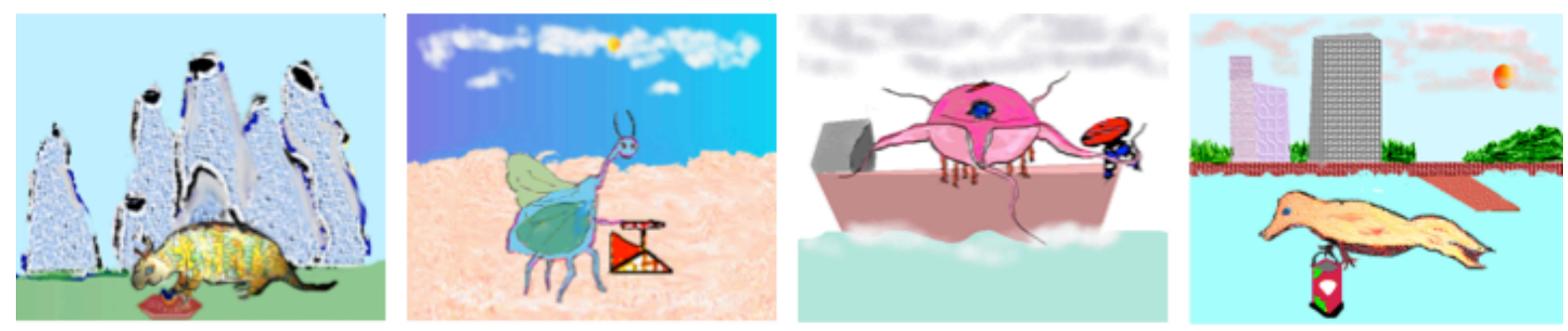

\section{Comparison Pictures}

Figure 3. One of five FIM-Animates test sets in the, with example prompts from three trials. Top left image = Standard; comparison items (bottom) from left: same- -species, same-habitat, samepossession, distracter. Blocks include five trials, one per set, with the same cue. In the example, finnet, toma and eland would generalize to, respectively, the first, second, and third items from left.

The other FIM test presents words for properties of animate creatures, or FIM-An (Deák \& Narasimham, 2013). Children hear three novel words for pictorial stimuli, each showing a creature in an alien environment holding a novel object (Figure 3). The novel words for each standard follow, on different trials, three different phrase cues: "is a," "lives in a," or "holds a." Again, children can use the cues to infer each word's referent, and identify another picture with 
that property. This tests a similar kind of flexibility as the FIM-Ob, but with different stimulus categories, materials, cues, and properties. Preschoolers' flexibility in the FIM-Ob and FIM-An are moderately strongly correlated (Deák \& Narasimham, 2013), even with age and receptive vocabulary controlled. The current study will replicate that finding, with procedural modifications.

Although the FIM-An and FIM-Ob both are cue-induction tests and the 3DCCS is a ruleswitching test, the FIM-An and 3DCCS share other features: their stimuli come from the same domain (biological kinds), and share the same medium (colored pictures). These similarities might contribute to between-test associations. However, all tests differ in specific cues/rules, stimuli, and properties, so if they are correlated, it could imply a general cognitive trait.

All three tests require receptive language ability to process cues or rules. This ability varies across children, so participants completed the Peabody Picture Vocabulary Test, a normed receptive language test (Dunn \& Dunn, 1997). To assess whether conceptual knowledge predicts flexibility, we selected an age-appropriate test of conceptual knowledge. Das Gupta and Bryant (1989) showed children object transformations of varying typicality, and asked them to select the likely instrument of transformation. Although it directly assesses only a narrow range of conceptual content, this test might assess variance in conceptual knowledge more broadly. In addition, children's accuracy in the first block of each flexibility test provides converging evidence of their task-relevant linguistic and conceptual knowledge.

Children completed several EF tests. Based on a hypothesis that task-switching demands inhibitory processes (Miyake et al, 2000; Zelazo et al, 2003), children completed two ageappropriate tests of cognitive and behavioral inhibition: one that requires inhibiting strong verbal associations, the Stroop Day/Night test (Gerstadt, Hong \& Diamond, 1994), and one that requires 
inhibiting an imitative tendency, Luria's Tapping test (Luria, 1966). Also, based on models that task-switching requires working memory activation and maintenance of the current rule (e.g., Baddeley, Chincotta \& Adlam, 2001; Cepeda et al, 2000), children completed a test of verbal working memory, Memory for Names (Woodcock \& Johnson 1989). Finally, processing speed is a task-general individual difference that modulates cognitive control (Kail, 1991; Kail \& Hall, 1994); here we consider it an EF parameter. Response speed was assessed with the Box Completion test (Salthouse, 1994), which can be administered to young children.

Although these measures barely tap the range of cognitive capacities that might relate to cognitive flexibility, ${ }^{2}$ they serve as a starting point: if any are consistently associated with the flexibility tests, it will suggest a relation that merits further investigation.

\section{Method}

\section{Participants}

Ninety-three 3- and 4-year-olds were recruited from local preschools; 85 completed all three sessions. Eight children were excluded due to absence or refusal to participate in one or more session. Also, a replication group of 12 3- and 4-year-olds was recruited after the main study to test for the possibility of order effects: these children completed all tests in a different order. Two children did not complete all sessions, leaving 10 children (6 girls) in the replication group (five 3-year-olds; five 4-year-olds). Extensive comparisons for differences between the main group and replication group revealed almost identical performance on all tests. Thus, their

\footnotetext{
${ }^{2}$ We assessed one other capacity: children's awareness of indeterminacy (Klahr \& Chen, 2003). Deák and Enright (2006) found that this was correlated with children's ability to switch answers to similar but distinct questions. We therefore administered an expanded set of questions like those in Deák and Enright (2006). However, the results showed a large floor effect, suggesting that the expanded test was too difficult. Thus, the results unfortunately are not informative, and will not be considered further.
} 
data were pooled and analyzed as a single group of $N=95$ children $^{3}$ ( 47 girls; mean age $=49$ months, range $=36$ to 59 ). Children were tested in their preschool. All procedures were approved by the university's IRB.

Most parents (75, or 79\%) completed and returned a questionnaire about family demographics and child history. (Children whose parents did not return it performed no differently on any test than children whose parents did return it.) Children's ethnic distribution was 7\% Asian, 23\% multiracial/‘other', 3\% white/Hispanic, and 68\% white/non-Hispanic. Parents mean age was 39 years $(S D=4)$, with 17 years of education $(S D=2)$. Most children (89\%) lived with two caregivers. Most children (61\%) had one sibling, 13\% were singletons, and $25 \%$ had two or more siblings. No child had any known sensory or cognitive problems, except one child with corrected vision. Mean gestational age was -0.6 weeks from term $(S D=1.8)$, and birth weight (reported for only 58 children) averaged $3.3 \mathrm{~kg}(S D=0.6 \mathrm{~kg})$, comparable to the United States median in 2012 (3.25 kg; CDC, 2013). One child had a (minor) birth complication. All children spoke English fluently; 38\% had exposure to a second language. PPVT-3 scores indicated that children with second language exposure did not differ from those without (secondlanguage exposure mean=108.4, $S D=11.7$; English-only $=109.3, S D=11.0$ ).

\section{Overall Design and Procedure}

Children participated in a quiet room in their preschool. Each child completed three sessions (typically 30-45 min long) within two weeks. Tests were presented in the same order to all children, to avoid order effects. The orders for the main and replication samples are shown in

\footnotetext{
${ }^{3}$ This does not affect any of the results below; it simply increases statistical power. Nonetheless, details of group performance are available from the corresponding author. The reason for this design was that if there were order effects, randomizing test order would have rendered the data ambiguous. A consistent test order allowed comparison of individual differences. The replication group provided a check for order effects that could have limited the interpretability of the results.
} 
Appendix A. Orders were quasi-randomly determined with several constraints: flexibility tests were in different sessions. The replication order was also constrained so each test was switched to a new session, in a different ordinal position, with different preceding and following tests. (Another test not reported here measured children's tool-using flexibility. There were no strong associations between it and the other flexibility tests. For that reason, and because it was rather elaborate, it will be described elsewhere [Deák \& Bodduppalli, submitted]).

One concern was that children might respond similarly across flexibility tests if the testing situation primes response strategies from the previous test session(s). Any such betweensession situational priming could spuriously increase between-test correlations. To control this, we changed the context across sessions: first, a different experimenter administered each session (experimenters were randomly assigned to sessions 1-3 across children). To ensure consistency across experimenters, a senior researcher watched videos of every session. Second, the testing table was rotated and covered with a different color tablecloth, to alter the visual context. These changes in the social and perceptual context across sessions should reduce between-session contextual priming. To our knowledge, no other study of children's cognition has taken such measures to control spurious shared variance due to priming over repeated testing.

\section{Cognitive Flexibility Tests}

Children completed three verbally cued flexibility tests (i.e., 3DCCS, FIM-Ob, and FIMAn). Each test included three blocks of trials defined by different phrase cues or rules. The same stimuli were shown in each block, and across blocks children could switch responses correctly or incorrectly, or repeat a prior response. To ensure that first-block responses were accurate, and ensure that all children built a response habit during this block, the strongest (i.e., easiest) cue from each test was assigned to the first block, the next-strongest cue to the second block, and the 
weakest cue to the last block (cue strength was based on data from Deák, 2000; Deák \& Narasimham, 2003, 2013; Narasimham et al., in review). This design holds order-by-difficulty interactions constant across children and tests. It also maximizes the probability that every child has many opportunities to switch responses. This is critical for making measures of flexibility (described below) interpretable. The cue order in the FIM-Ob was "is made of," "has a," and "is shaped like a"; in the FIM-An was "is a," "holds a," and "lives [in/on] a." The rule order in the 3DCCS was shape, color, and size.

Stimulus order in each test was randomized for each child and repeated across blocks. Children received non-specific feedback for every response (i.e., “Thank you."). The experimenter maintained eye contact with the child during every trial, and used a uniform tone of voice to avoid providing differential feedback.

Three Dimension Changes Card Sorting (3DCCS). Photoshop-modified clip art images printed on laminated $21 \mathrm{~cm}^{2}$ cards depicted prototypical familiar animals (dog, fish, and bird) in three focal colors (red, blue, and yellow) and three sizes (approximately $3.3 \mathrm{~cm}^{2}, 8.9 \mathrm{~cm}^{2}$, and $17.2 \mathrm{~cm}^{2}$ ). A fourth distracter showed a medium-large green frog. (Stimuli are available at cogdevlab.ucsd.edu.) Distracters were used in each test to check that children were attentive and compliant. Children sorted five test cards into four white cardboard boxes, each with a different standard on top. For each test card, one standard had the same shape, one the same color, and one the same size, as shown in Figure 1. Standards differed in all property values so any match was unambiguous. Each test card had different combinations of properties than any standard, so it would go in a different box under every rule. Test cards were randomized for each child, but any property occurred no more than twice, and no two properties (e.g., small + blue) were combined more than once. Before the test children were asked to label the animal, color, and size properties 
of each card to ensure that they knew the relevant labels (e.g., blue, fish), and understood the game labels (e.g., "color game”). All children demonstrated comprehension. The rules of the first game were stated three times, using different phrasings. Key instructions from the flexibility tests are provided in Appendix B. Before the test trials children were asked to re-state the rules and answer several rule-comprehension questions (based on Zelazo, 2006). Before the second and third blocks children were told (three times) to stop playing the old game and start playing a new game. New rule was explained, and children's comprehension was checked.

Children sorted each of the five cards three times, once per rule (animal, color, or size game). Specific sub-task rules (e.g., "dogs go in this box") explicitly indicated where to place each card in a given block.

Flexible Induction of Meaning -Objects. Five sets of novel objects each included a standard and four comparison objects. Each standard matched one of three comparison objects on one of three novel properties: shape, material, or affixed part. The fourth object in each set was a distracter (Figure 2 and Deák, 2000). In each of 15 test trials children were told to look at all the objects, then the experimenter said (twice), of the standard, either, "This is made of

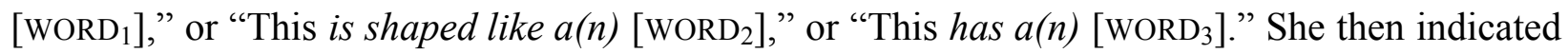
the comparison objects and asked "Which one of these also [CUE] [WORD]?" The prompt was repeated after $8 \mathrm{sec}$ if a child did not answer. Each block featured a different phrase cue. Object positions were randomized on each trial and words were randomly assigned to properties.

Flexible Induction of Meaning-Animates. The FIM-An test used five sets of five color pictures $\left(12.5 \mathrm{~cm}^{2}\right.$ ) of novel creatures (some from Barlow \& Summer, 1979) holding novel objects in novel habitats (Figure 31 Deák \& Narasimham, 2013). (Stimuli available at cogdevlab.ucsd.edu). Each set's Standard matched one of three comparison pictures on one of 
three properties: species, habitat, or held object. The fourth distracter had different properties. (Stimuli are available at cogdevlab.ucsd.edu.) In each of 15 trials, children were first told to look at the pictures, then the experimenter said of the standard either "This is a(n) [NOVEL WORD $]$," or "This lives in/on a(n) [WORD 2 ," or "This holds a(n) [WORD 3 ." She then indicated the comparison pictures and asked, "Which of these also [CUE] [WORD]?" Each block featured a different phrase cue. Picture positions and words were randomized as in the FIM-Ob.

Scoring: Flexibility tests. Each flexibility test was evaluated using three measures. First, accuracy was coded as the number of cue- or rule-appropriate responses in each block, and in total. Total accuracy indicates sensitivity to cues or rules. Also, accuracy in the first block across tests provides an index of children's ability to comprehend cues/rules.

Second, flexibility was assessed using a more focused measure that allows comparison across tests: CORSWOPS (correct switches/opportunities; Deák \& Narasimham, 2013), or the proportion of correct switches in later blocks, corrected for opportunities to switch correctly. This is the proportion of trials in blocks two and three when the child chose a cue- or ruleappropriate item that was different than the previous item chosen from that set. Because accuracy in blocks one and two can vary, the proportion of possible correct switches can differ in block two and three. Correcting for the actual number of opportunities to switch correctly provides an index of flexibility that is less biased by age and other factors. ${ }^{4}$ Although CORSWOPS is strongly correlated with total correct responses, it controls for variability in initial accuracy across children. CORSWOPS is a general index that can be compared across any flexibility test that meets a few assumptions: discrete correct and incorrect responses, and sufficient post-switch

\footnotetext{
${ }^{4}$ CORSWOPS does not count trials in which a child repeats a response that was first inappropriate, but became appropriate after the cue-switch. Even if the second response is 'correct,' it is not counted as a correct switch because there was no opportunity to switch correctly, and no way to distinguish flexible from perseverative responding. It is most conservative to exclude these responses entirely. Forturnately these cases are rare (mean $=5.4 \%$ of post-switch responses overall), and do not affect the results.
} 
opportunities to derive proportional scores. These assumptions are met by all three tests. For example, even the youngest quartile of our sample (43 months or younger) had enough opportunities to switch (means $=94 \%$ of post-switch 3 DCCS trials, $79 \%$ of FIM-Ob trials, and 99\% of FIM-An trials) to derive meaningful CORSWOPS proportions.

Third, children's responses across trials of any flexibility test usually fit some sequential pattern. In previous studies (Deák, 2000; Deák \& Narasimham, 2013) children's response patterns could be classified as flexible (in the current design with three blocks of five trials, this entails 13 or more correct choices, with 7 or more correct switches), partly flexible (9-12 correct choices, 5 or more correct switches), perseverative (7 or fewer correct choices; 3 or fewer switches [correct or not]), or indiscriminate (10 or fewer correct, 4 or more switches, but 3 or fewer correct switches). These categories might reflect different approaches to the test: the flexible patterns indicates adaptation to each cue/rule, partly flexible patterns reflect adaptation to two of three cues/rules, or inconsistent use of each cue/rule, perhaps with high uncertainty; perseverative patterns reflect either failure to encode cue/rule changes or failure to weight later cues/rules higher than previous responses; indiscriminate patterns might reflect high uncertainty about mappings of cues/rules to stimulus properties. These patterns therefore suggest different sources of error that are not discerned by parametric measures.

\section{Cognitive Tests: Executive Functions and Knowledge}

Response Speed: Box Completion. Children saw a page with 35 three-sided boxes (Salthouse, 1994), each missing a randomly chosen side. Children were instructed to "close" each box by drawing a line across the open side. After doing a practice sheet, children completed as many boxes as possible within $60 \mathrm{sec}$. We report the number completed in the first $30 \mathrm{sec}$, which is less affected by conflating variables such as vigilance, distraction, and boredom. 
Working Memory: Memory for Names (Woodcock \& Johnson, 1989) Children heard names for a series of alien creatures, and then identified each alien by name. After each trial a new name was added, so memory load gradually increased. Testing continued until the child exceeded a specified number of errors (see Dean \& Woodcock, 1999).

Inhibition (Lexical): Stroop Day/Night. Children were instructed to say the word "day" when shown a picture of the moon, or "night" when shown a picture of the sun (Diamond, Kirkham, \& Amso, 2002; Gerstadt, Hong, \& Diamond, 1994). After completing up to six practice trials with feedback, children completed two blocks of 10 trials in quasi-random order, without feedback.

Inhibition (Action): Tapping. Following Luria (1966; Diamond \& Taylor, 1996), children were instructed to tap once (with a plastic rod) if the experimenter tapped twice, and tap twice if she tapped once. After practice trials with feedback, children completed two blocks of 10 trials in quasi-random order, without feedback.

Lexical Knowledge: Receptive Vocabulary. The PPVT-3 was administered according to standard procedures (Dunn \& Dunn, 1997).

Conceptual Knowledge: Causal Inference. Based on Das Gupta and Bryant (1989), we showed children photographs $\left(16 \mathrm{~cm}^{2}\right)$ that implied events in which objects underwent changes (e.g., broken flowerpot and glued-together flowerpot). The experimenter described the pictures in general terms ("Look at this. First it looked like this... Then I did something to it, and now it looks like this."). Children then were shown photographs of four possible instruments (e.g., hammer, light bulb, brush, glue), and were asked to choose the one that caused the change ("Which of these things... [made] it like this?"). Children completed two practice trials with feedback, then eight test problems without feedback, including four easier problems and four 
harder ones (see Das Gupta \& Bryant, 1989), to increase variability in accuracy. Items are described in Appendix C. Item order and picture position was randomized for every child. Scoring

All responses were coded on-line by a second researcher. Videotapes were re-coded for accuracy by an independent researcher. On-line accuracy was $>98 \%$. Box completion scores were the number of boxes 'closed' in $30 \mathrm{~s}$. Standard scoring rules were used for Memory for Names and PPVT; total correct was calculated for Stroop, Tapping, and Causal Reasoning.

\section{Results}

The main and replication groups performed nearly identically on all tests (all $t \mathrm{~s}<1.5$ ), so they were combined in all further analyses $(N=95)$. There were no gender effects on any task (all $t \mathrm{~s}<1$ ), so girls and boys were combined.

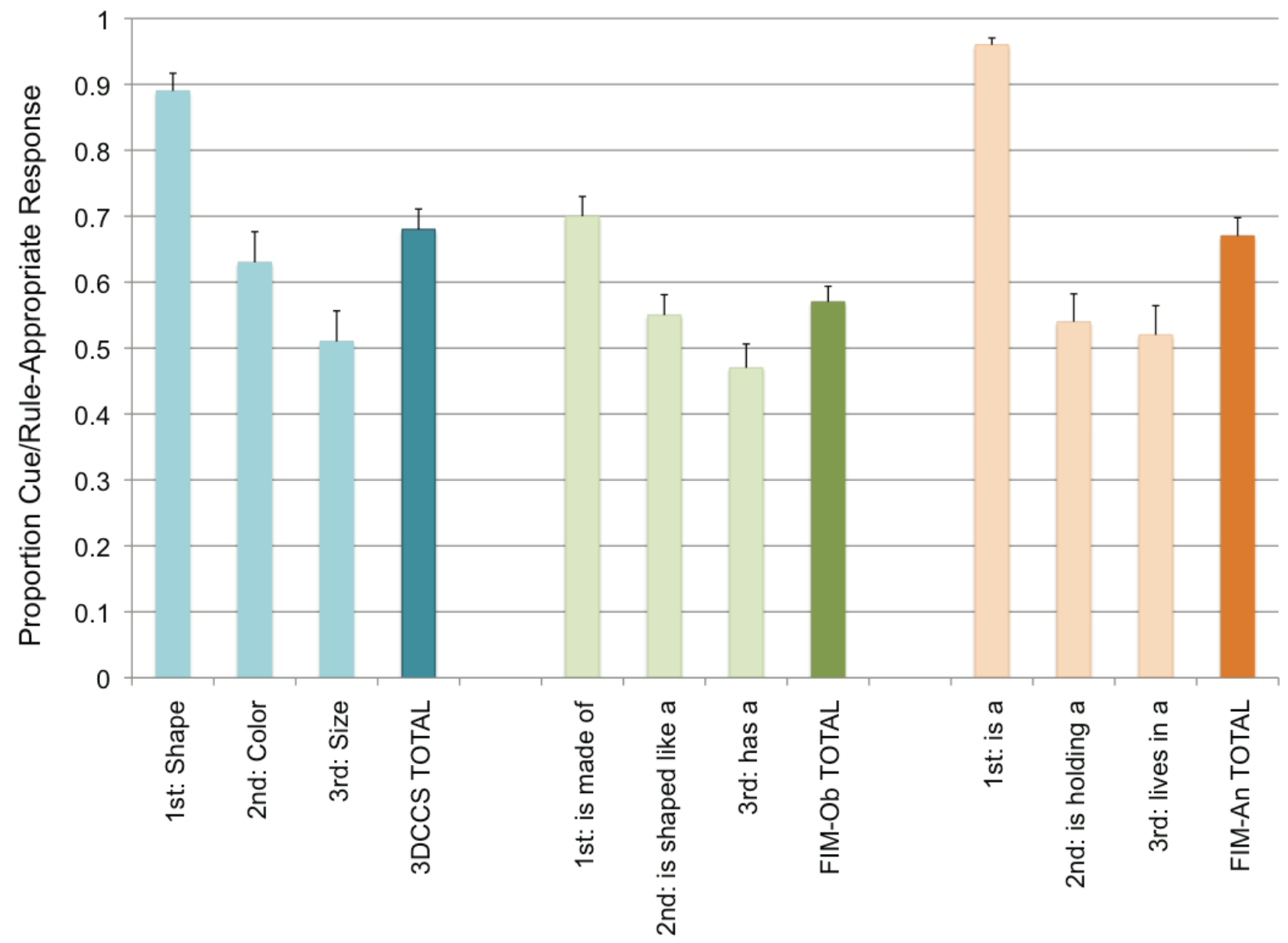


Figure 4. Mean appropriate responses to each rule or cue in the 3DCCS, FIM-Ob, and FIM-An tests, and total appropriate responses. A decline in later blocks is apparent . Error bars $=S E$ of mean.

\section{Flexibility Task Performance}

Cue/rule accuracy is shown in Figure 4. Mean accuracy in each test was higher in block 1 than in blocks 2-3. This could be due to limitations in flexibility, increasing difficulty of later cues/rules, or both. All three tests show a negative quadratic trend across blocks in repeatedmeasure ANOVAs (with Greenhouse-Geisser correction). The within-subjects effect was significant in the 3DCCS, $F(1.3,124)=38.4, p<.001, \eta^{2}=.29$, in the FIM-Ob, $F(1.9,179)=$ $16.8, p<.001, \eta^{2}=.15$, and in the FIM-An, $F(1.7,159)=92.6, p<.001, \eta^{2}=.50$.

Although the tests were designed to have similar difficulty, FIM-Ob accuracy was lower (mean correct $=57.4 \%, S D=22.6 \%)$ than FIM-An accuracy $(67.3 \%, 27.2 \%)$ or 3DCCS accuracy $(68.4 \%, 29.6 \%)$, Oneway ANOVA: $F(2,188)=10.6, p<.001$. However, this is not a major interpretative problem because the mean difference is only $11 \%$, and variance is similar across tests, with no ceiling or floor effects.

Flexibility was similar across tests: mean CORSWOPS was $54.6 \%$ in the 3 DCCS $(S D=$ $42.3 \%), 47.1 \%$ in FIM-Ob $(32.7 \%)$, and 53.2\% in FIM-An $(39.5 \%), F(2,188)=1.9, p=.148, n s$ by Oneway ANOVA. Correlations of age and flexibility (CORSWOPS) also were similar across tests: $r=.498$ in FIM-Ob, $r=.532$ in FIM-An, and $r=.500$ in 3DCCS (all $p$ s $<.001$ ). Figure 5 shows the distribution of CORSWOPS by age in each test. No test shows a non-linear inflection or bimodal distribution that would indicate a qualitative shift between 3 and 4 years.

Figure 5. Scatterplots of CORSWOPS in three flexibility tests, with regression lines: FIM-Ob (top), FIM-An (middle), and 3DCCS (bottom). Scores are arranged by age. The best-fitting trend for each test is nearly linear. No discontinuity between 3- and 4-year-olds (e.g., perseverative vs. flexible) is evident, contrary to a possible interpretation of results from binary rule-switching tests (e.g., DCCS). 

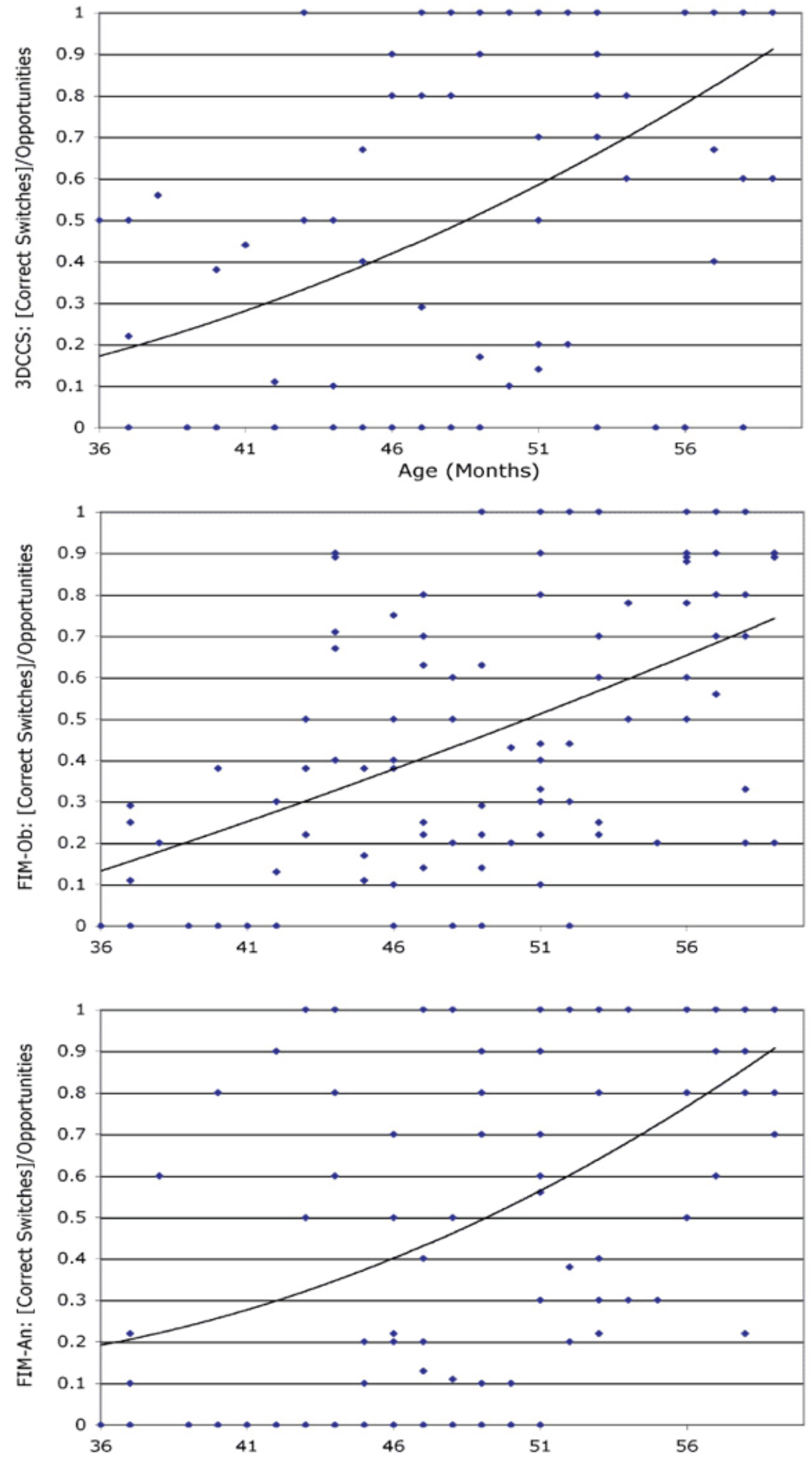
Individual differences in flexibility are also evident in qualitative response patterns. Numbers of children producing each of four patterns in each test, and each pair of tests, is shown in Appendix D. The distribution differs across tests, $\chi^{2}(d f=6, N=95)=22.5, p<.001$. The distribution was similar in the FIM-An and 3DCCS: $42-45 \%$ of children were flexible, $13-14 \%$ partly flexible, $25-29 \%$ perseverative, and 13-19\% indiscriminate. By contrast, only $22 \%$ were flexible in the FIM-Ob, 54\% were partly flexible, and 37\% were indiscriminate, confirming that this test was harder. Despite this, as described below, children were more likely to produce the same response pattern across the two FIM tests.

\section{Coherence Between Flexibility Tasks}

Partial correlations with age removed, between CORSWOPS scores on the three flexibility tests, and EF and language/knowledge test scores, are shown in Table 1. Critical levels are $\alpha=.01$ to reduce test-wise Type I error rate. FIM-Ob and FIM-An were strongly related, $r_{\text {part. }}=.61\left(p<.001 ; R^{2}=.37\right)$. FIM-Ob and 3DCCS were reliably but weakly correlated,: $r_{\text {part }}=$ $.27\left(p=.009 ; R^{2}=.07\right)$. FIM-An and 3DCCS were not significantly related, $r_{p a r t}=.12(p=.255)$.

To verify the robustness of these results, we explored partial correlations using alternate measures including: number of correct switches in flexibility tests, uncorrected for number of opportunities; z-scores instead of totals for the inhibition tests, and raw PPVT scores. In all cases the coefficients were nearly identical, and retained the same level of statistical significance. 
Table 1. Partial correlations, controlling for age, among flexibility tests (bold outline), EF measures (Box Completion [speed], Stroop Day-Night [verbal inhibition], Tapping [action inhibition], Memory for Names [working memory]), and knowledge tests (PPVT; causal inference).

\begin{tabular}{|l|c|c|c|c|c|c|c|c|}
\hline Correlation & $\mathbf{2}$ & $\mathbf{3}$ & $\mathbf{4}$ & $\mathbf{5}$ & $\mathbf{6}$ & $\mathbf{7}$ & $\mathbf{8}$ & $\begin{array}{c}\text { Causal } \\
\text { Infer. }\end{array}$ \\
\hline 1. FIM-Ob & $.61^{* * *}$ & $.27^{*}$ & $.31^{* *}$ & $.28^{*}$ & $.30^{* *}$ & .13 & $.30^{* *}$ & $.31^{* *}$ \\
\hline 2. FIM-An & & .12 & $.30^{* *}$ & .19 & .23 & .04 & $.35^{* * *}$ & $.27^{*}$ \\
\hline 3. 3DCCS & & & .26 & .17 & .24 & .06 & $.31^{* *}$ & $.41^{* * *}$ \\
\hline 4. Boxes & & & & .16 & .07 & .08 & .07 & .21 \\
\hline 5. Stroop D/N & & & & & $.43^{* * *}$ & $.32^{* *}$ & .21 & .05 \\
\hline 6. Tapping & & & & & & $.33^{* *}$ & $.51^{* * *}$ & .26 \\
\hline 7. Mem. Name & & & & & & & $.32^{* *}$ & -.02 \\
\hline 8. PPVT-3 & & & & & & & & $.38^{* * *}$ \\
\hline
\end{tabular}

Note. ${ }^{*} p<.01 ; * * p<.005 ; * * * p<.001$. Dependent measures: FIM-Ob, FIM-An, and 3DCCS: CORSWOPS; W-J Boxes: boxes completed in $30 \mathrm{sec}$; Stroop and Tapping: total correct; Memory for Names and PPVT-3: standardized scores; Causal Reasoning: total correct.

We also tested whether verbal knowledge (e.g., cue/rule comprehension) could explain the strong association between FIM tests. Partial correlations among flexibility tests (CORSWOPS) were calculated, with age, vocabulary, and correct first-block responses on all three tests (indicating cue/rule comprehension) partialled out. The correlation between FIM tests remained strong, $r_{\text {part. }}=.64\left(p<.001 ; R^{2}=.41\right)$. The relation between FIM-Ob and 3DCCS remained reliable but weak, $r_{\text {part. }}=.28\left(p=.007, R^{2}=.08\right)$. The relation between FIM-An and 3DCCS remained non-significant $r_{\text {part. }}=.08(n s)$. These results indicate that cue comprehension cannot explain consistency between FIM tests.

We also examined consistency in individual children's response patterns (flexible, partly flexible, perseverative, indiscriminate) between tests. Appendix D shows the numbers of children who produced the same patterns on each pair of test. On the FIM-Ob and FIM-An tests, $48.4 \%$ of 
children (46) produced the same pattern-twice the percentage expected $(24.7 \%)$ based on marginal cross-products, and nearly identical to the proportion $(50 \%)$ reported by Deák and Narasimham (2013). By contrast, only 30.5\% of children (29) produced the same pattern on the FIM-Ob and 3DCCS, just slightly above the expected number (23.9\%). Finally, 38.9\% (37) produced the same pattern on the FIM-An and 3DCCS, also just slightly above the expected number $(30.6 \%)$. Thus, only the FIM tests yielded more concordant response-patterns than expected.

\section{Executive Function and Reasoning Tests}

Results from EF tests and language/conceptual knowledge tests are shown in Table 2. Age was significantly related to response speed, lexical and action inhibition, verbal working memory, and causal inference. Standardized PPVT-3 scores indicate that the sample had somewhat higher lexical knowledge than norming samples.

Table 2. Children's performance on EF and language/conceptual knowledge tests. Pearson's correlations with age are shown, with $p$-values. Last columns summarize regressions (see text).

\begin{tabular}{|c|c|c|c|c|c|}
\hline TEST & $\begin{array}{l}\text { Mean Score } \\
\text { (SD) }\end{array}$ & $\begin{array}{c}\text { Correlation } \\
\text { with age }\end{array}$ & $\begin{array}{c}\text { FIM-Ob } \\
\text { predictor } \beta\end{array}$ & $\begin{array}{c}\text { FIM-An } \\
\text { predictor } \beta\end{array}$ & $\begin{array}{c}3 D C C S \\
\text { predictor } \beta\end{array}$ \\
\hline $\begin{array}{l}\text { Response Speed } \\
\text { (Box Completion) }\end{array}$ & $\begin{array}{c}13.6 \\
S D=4.8\end{array}$ & $\begin{array}{c}r=.55 \\
p<.001\end{array}$ & .22 & .29 & .18 \\
\hline $\begin{array}{l}\text { Inhibition/verbal } \\
\text { (Stroop Day/Night) }\end{array}$ & $\begin{array}{c}13.4 \\
5.0\end{array}$ & $\begin{array}{c}.29 \\
p=.005\end{array}$ & .29 & & \\
\hline $\begin{array}{l}\text { Inhibition/Action } \\
\text { (Luria Tapping Test) }\end{array}$ & $\begin{array}{c}13.0 \\
5.7\end{array}$ & $\begin{array}{c}.63 \\
p<.001\end{array}$ & .19 & & .25 \\
\hline $\begin{array}{l}\text { Verbal Working Memory } \\
\text { (Memory for names) }\end{array}$ & $\begin{array}{l}34.3 \\
14.1\end{array}$ & $\begin{array}{c}.33 \\
p<.001\end{array}$ & & & \\
\hline $\begin{array}{c}\text { PPVT-3 } \\
\text { (Lexical knowledge) }\end{array}$ & $\begin{array}{c}109.8 \\
12.5\end{array}$ & $\begin{array}{c}.16 \\
p=.122\end{array}$ & .18 & .53 & \\
\hline $\begin{array}{c}\text { Causal Inference } \\
\text { das Gupta \& Bryant, } 1989\end{array}$ & $\begin{array}{l}4.94 \\
1.86\end{array}$ & $\begin{array}{c}.55 \\
p<.001\end{array}$ & .50 & & .56 \\
\hline
\end{tabular}

Note. Scores: Boxes completed (30 sec), Inhibition tests total correct, Memory for Names calculated score, PPVT standardized score, Causal Inference total correct. Regression summary columns show 
marginal or significant adjusted $\beta$ weights (all others $n s$ ).

To explore how these measures related to flexibility, we ran step-wise regressions on CORSWOPS in each test, entering age and the main dependent measure from each EF or knowledge test. Criterion for entry was set at $\alpha=.05$.

For FIM-Ob, three factors significantly and uniquely predicted flexibility: causal inference (step $\left.1, \beta_{S t d}=.50, t=5.3, R^{2}=.249, p<.001\right)$, verbal inhibition/Stroop (step $2, \beta_{S t d}=$ $\left..295, t=3.2, R_{\text {change }}^{2}=.083, p=.002\right)$, and response speed/Boxes (step 3, $\beta_{S t d}=.22, t=2.2, p=$ $\left..031, R_{\text {change }}^{2}=.037, p=.031\right)$. The three-factor model accounted for $R_{\text {Adjusted }}^{2}=.346(S E=.26)$, $F(1,83)=16.2, p<.001$. Two other factors were marginally significant: vocabulary/PPVT, $\beta=$ $.182, t=1.7, p=.086$, and action inhibition/Tapping, $\beta=.195, t=1.7, p=.089$.

For FIM-An, two factors significantly and uniquely predicted flexibility: vocabulary (step $\left.1, \beta_{\text {Std }}=.53, t=5.7, R_{\text {Adj }}^{2}=.271, p<.001\right)$, and response speed (step 2, $\beta_{\text {Std }}=.29, t=3.1, R_{\text {change }}^{2}$ $=.075, p<.001)$. The two-factor model accounted for $R_{A d j}^{2}=.339(S E=.319) F(1,84)=23.1, p$ $<.001$. Another factor, age, was marginally significant: $\beta=.215, t=1.9, p=.057$.

For 3DCCS, two factors predicted flexibility: causal inference (step $1, \beta_{S t d}=.56, t=6.2$, $R_{A d j}^{2}=.304, p<.001$ ), and action inhibition/Tapping (step 2, $\beta_{S t d}=.25, t=2.5, R_{\text {change }}^{2}=.047, p$ $=.015)$. These accounted for $R_{A d j}^{2}=.344(S E=341), F(1,84)=23.5, p<.001$. Another factor, response speed/Boxes, was marginally significant: $\beta=.184, t=1.9, p=.066$.

We previously found that the FIM tests were strongly correlated. The regression results suggest that some common predictor abilities might explain the correlation between FIM tests. To assess this, we calculated partial correlations among flexibility tests (CORSWOPS), removing not only age, but also any factor that predicted significant variance in multiple flexibility tests: response speed, action inhibition, causal reasoning, and vocabulary. With all of 
these factors partialled out, the strong association between FIM tests remained, $r_{\text {part. }}=.63(p<$ $.001 ; R^{2}=.40$ ), as did the weak partial correlation between the FIM-Ob and 3DCCS tests, $r_{\text {part }}=$ $.22\left(p=.037 ; R^{2}=.05\right)$. The former is significantly stronger than the latter, $z=3.5$ by Fisher transformation, $p<.001$. The correlation between FIM-An and 3DCCS remained nonsignificant, $r_{\text {part }}=.03$.

\section{Discussion}

This study compared English-speaking preschool children's performance on three flexibility tests, in relation to 'executive functions' and verbal and conceptual knowledge. There was a strong correlation between two tests of flexible cue-induction of word-meanings, independent of variance due to age, response speed, inhibition, and verbal knowledge. Flexibility in one cue-induction test, the FIM-Ob, was also correlated with flexibility in the rule-switching 3DCCS test. However, this correlation was significantly weaker $\left(R^{2}=.05\right)$. Also, children tended to produce the same response patterns on both FIM tests, but were no more likely than chance to produce the same pattern on an FIM test and the 3DCCS. Thus, parametric and categorical measures both suggest that individual cue-induction flexibility for word meanings was highly stable across tests, and at most reliably but weakly related to flexible rule-switching. This was true even though the FIM-An was more similar to the 3DCCS in overall difficulty and in some methodological factors (e.g., stimulus material; stimulus domain).

One interpretation is that some underlying capacity contributes to high individual stability of cue-induction flexibility for meaning interpretation, but not to rule-switching flexibility. We cannot say how general the capacity is: it might pertain just to word meanings, or to broader semantic inferences, or perhaps to a variety of probabilistic cues (even, e.g., nonverbal information). Regardless, the results show that it is inappropriate to treat a single test of 
flexibility in children as measuring some general capacity. This confirms other recent evidence: Ramscar et al (2013) showed that at least two processes contribute to children's rule-switching flexibility, explaining why different DCCS versions yield different results (e.g., Perner \& Lang, 2002). Also, adult studies suggest that flexibility is task-dependent (e.g., Kim et al, 2011; Luwel et al., 2003; Ravizza \& Carter, 2008).

Could the correlation between FIM-An and FIM-Ob flexibility be due to shared method variance instead of cue-induction flexibility? We cannot entirely rule this out, but it is noteworthy that all stimulus items, the stimulus medium (pictures vs. objects), key stimulus properties, verbal cues, the content domain, and the words themselves were all entirely different between tests. Also, the tests were administered on different days, by different experimenters, in a different visual environment. Thus, many aspects of the test were changed. However, some aspects were similar across FIM tests: on every trial the experimenter presented a novel multidimensional stimulus, told the child a new fact about it, including a novel word, and asked the child to generalize the word to one of four other stimuli. These methodological similarities might have contributed to the between-test correlation. It will require further investigation to completely separate the causes of shared variance. However, even if some portion of shared variance is due to shared methods variance, it would strengthen one conclusion from this study: that cognitive flexibility cannot be considered a global executive capacity in children, and should not be estimated from a single test measure. After all, when intercorrelated factors are partialled out, the FIM tests share less than $40 \%$ of variance.

Relations to Executive Functions. The results also address how several EFs (processing speed, inhibition, verbal working memory) relate to children's flexibility. If any EF had a consistent relation with all flexibility tests, it would suggest a stable underlying factor or 
contributor to task-general flexibility processes (Miyake et al, 2000). The results are equivocal: regression analyses showed a different subset of predictors of each flexibility test, failing to confirm a general underlying processing model. However, response speed was a significant or marginal unique predictor of flexibility in all three tests. This supports the view that processing speed is a unique, general predictor of higher-order cognitive and linguistic processes and fluid intelligence (e.g., Kail \& Hall, 1994; Li, Lindenberger et al.; 2004; Salthouse et al., 1998), and more specifically a predictor of older children's cognitive flexibility, at least in rule-switching tests (Cepeda et al., 2000). A recent study (Holt \& Deák, 2014) extended this finding to preschool-aged children. However, in the current study, response speed in a visuo-motor test (box completion) only marginally predicted rule-switching flexibility. Similarly, Cepeda and Munakata (2007) did not find that 5-6-year-olds' speed uniquely predicted their flexibility in a computerized 3DCCS test. Thus, the relation between response speed and rule-switching is not consistent across studies. Because studies have used different measures of speed and ruleswitching, and different age ranges, it is currently impossible to determine why this is so. That would require a study with multiple measures of both factors, with varied task demands.

Cognitive inhibition has been hypothesized to contribute to cognitive flexibility. However, the present results suggest that children's flexibility is not restricted by their ability to inhibit 'prepotent' responses. The Stroop Day-Night test, which requires inhibiting and reversing verbal associations (Simpson \& Riggs, 2005), predicted 8\% of variance in FIM-Ob, and did not predict unique FIM-An or 3DCCS variance. Deák and Narasimham $(2003,2013)$ also found no relation between the Stroop Day/Night and FIM-Ob or FIM-An tests. Because the current finding of a weak but reliable correlation between the Stroop and FIM-Ob is inconsistent with those previous results, this might indicate a context-specific association, or sampling error. Regardless, 
the sum of available evidence does not suggest that inhibitory processes are a limiting factor in young children's flexibility.

Luria's Tapping test, which requires children to inhibit action imitation, was a reliable but minor predictor $\left(R^{2}=.05\right)$ of $3 \mathrm{DCCS}$ flexibility and a marginal predictor of FIM-Ob flexibility. In spite of this, there are limitations of inhibition-based explanations of children's cognitive flexibility. One is that cognitive inhibition itself might not be a coherent trait. Although the Stroop and Tapping tests were correlated in the current data (see also Montgomery \& Koeltzow, 2010), they shared only $18 \%$ variance, suggesting mostly unique, not common, processes. This confirms other evidence that children's performance varies considerably across inhibition tests (Carlson et al, 2002). One possible explanation is that there are multiple inhibitory processes that are all elicited to varying degrees by different tests of inhibition and (less directly) by different tests of flexibility, such that the association between any two tests cannot currently be predicted. This hypothesis has not been explored, but it is consistent with existing evidence (Blackwell, Chatham, Wiseheart, \& Munakata, 2014; Cepeda et al, 2000; Holt \& Deák, 2014). Also, although Zelazo et al (2003) claimed that negative priming, an inhibitory process, affects preschoolers' rule-switching, Ramscar et al (2013) show that the relevant findings can be explained by associative learning processes. In sum, previous and current results do not point to a clear, specific causal relation between developing inhibitory mechanisms and children's cognitive flexibility.

Recent evidence has suggested a relation between verbal working memory (vWM) efficiency and cognitive flexibility, in children as well as adults (Cepeda \& Munakata, 2007; Gruber \& Goschke, 2004; Holt \& Deák, 2014; Schneider \& Logan, 2009). However, we found no relation between Memory for Names performance and any flexibility measure. This is notable 
because the FIM tests could require vWM for novel words, and the 3DCCS requires vWM for the current rule. Yet these negative results converge with prior findings that children's vWM capacity does not predict their flexibility in verbally cued tests (Deák \& Narasimham, 2003; Zelazo et al., 2003). One possible reason for these negative findings is that vWM capacity is dissociated from vWM efficiency or specificity of retrieval and/or maintenance (e.g., Postle, Berger, \& D'Esposito, 1999). It seems children's cognitive flexibility is unrelated to variability in $\mathrm{vWM}$ capacity, but perhaps somewhat related to $\mathrm{vWM}$ efficiency or specificity. A question for future study is whether cue-induction and rule-switching flexibility are equally sensitive to differences in vWM processes related to updating, maintenance, or retrieval.

Relations to Knowledge. Cognitive flexibility is critical for everyday language use (Deák, 2003), and it requires semantic knowledge, at least when task cues are linguistic (see HermerVazquez et al, 2001). The flexibility tests here required comprehension of, and response to, verbal cues. Thus, any correlations between flexibility tests could have been due to receptive language knowledge. To test this, receptive vocabulary was assessed (Sattler, 2002). PPVT vocabulary predicted $27 \%$ of variance in FIM-An flexibility, and was a marginal predictor of FIM-Ob flexibility. Deák and Narasimham (2003) also found a marginally significant relation of vocabulary with FIM-Ob flexibility, but a non-significant (positive) correlation with FIM-An flexibility. Thus, there is some converging evidence, though not consistent, that individual differences in receptive language (vocabulary) predict children's cue-induction flexibility. However, even when variance from vocabulary was partialled out - along with accuracy in the first blocks of flexibility tests - a strong correlation remained between FIM tests, suggesting that verbal knowledge did not mediate the association. Note that the cues and rules were chosen to be comprehensible to typical 3-year-olds. Still, differences in children's certainty or speed of 
cue/rule processing might have affected their ability to use cues flexibly. However, the results do not support this hypothesis. Another interpretation of the correlation between vocabulary and FIM scores (though inconsistent) is that word-learning flexibility makes a small but cumulative contribution to children's vocabulary. That is, children who can more flexibly select changeable, probabilistic contextual cues to infer novel word meanings might acquire new words faster, all else being equal, than less flexible children.

It is also possible that conceptual knowledge contributes to cognitive flexibility. This hypothesis has received little attention (but see Bilalić, McLeod, \& Gobet, 2008). A test of causal inferences about object effects (das Gupta \& Bryant, 1989), with no flexibility demands and minimal verbal demands, uniquely predicted flexibility in FIM-Ob and 3DCCS. This is not predicted by current accounts (Deák, 2003; Zelazo et al, 2003). How can we explain it?

One possibility is that all three tasks share a demand to select one abstract similarity out of several that is most relevant to the given problem, and ignore at least two conflicting options in the stimulus array. The selections cannot rely on habitual responses or repetition, but on active inductive reasoning. Children might vary in this capacity, which is consistent with a description of 'fluid intelligence' by Horn and Cattell (1966:268): “perceiving relations, educing correlates, maintaining...awareness in reasoning, and abstracting...figural, symbolic, and semantic content." Although this explanation is descriptive, not explanatory, it points to other relevant efforts to elucidate the relation between concepts of fluid intelligence and executive functions (e.g., Decker, Hill \& Dean, 2007; Kane \& Engle, 2002). These efforts have yet to extend to research on the development of cognitive flexibility, but the current result suggests that this might be a fruitful research direction. However, note two the causal inference test was not significantly correlated with the FIM-An, so the finding might not be very general. Also, when 
causal inference scores were partialled out, the association FIM the tests remained strong, so it cannot fully explain the between-test coherence.

General implications: An interpretation consistent with all available data is that children's flexibility is determined by multiple factors, including: (1) processing factors related to task-type, for example cue-induction for inferences of meaning, or rule-switching; (2) sub-task specific factors (e.g., understanding specific cues or rules; e.g., Munakata \& Yerys, 2001); (3) cognitive moderators including response speed (Cepeda et al, 2001, 2013), working memory efficiency (Cepeda \& Munakata, 2007; Holt \& Deák, 2014), and possibly a faculty for selecting abstract relations for novel inferences (i.e., 'fluid intelligence'). These factors together predict considerably variability in children's flexibility.

The current results also confirm that children should not be classified simply as 'flexible' or 'perseverative.' That dichotomy is an artifact of low-sensitivity test designs (e.g., DCCS). Young children, like adults, produce distinct perseverative and indiscriminate error patterns. Barceló and Knight (2002) speculate that adult frontal patients' indiscriminate errors are related to WM inefficiency. It remains to be determined whether children produce indiscriminate response patterns due to inefficient vWM. However, most children $(80 \%)$ did not produce the same pattern on all three tests, suggesting that children's performance on a given flexibility test cannot be assumed to generalize, or to indicate a single, global deficit or immaturity.

The results also disconfirm an impression from the literature that cognitive flexibility improves qualitatively between three and four years. All three flexibility tests show a positive age-related trend, but it is nearly linear, with no inflections or discontinuity (Figure 5). Also, there was high inter-individual variability at any age stratum. Thus, although age predicts flexibility, it is a poor predictor by itself. 
The results leave unanswered questions for future research. One limitation is that this sample was restricted to healthy, English-speaking, middle-class North American children. It is unknown whether the results generalize to other populations. Also, we could not collect response times, eye movements, or physiological measures (e.g., EEG) that might reveal subtler but potentially predictive indicators of age and individual differences. A third limitation is that we used only single measures of executive functions (e.g., response speed; action inhibition). Single measures are non-optimal because any single test brings idiosyncratic measurement error; a latent variables approach is preferable. The current results therefore provide suggestions for future investigations rather than generalizable estimates of the associations among latent cognitive factors. Another limitation is that in all three flexibility tests the cue/rule order got progressively harder. Although this made between-test individual differences interpretable, it introduces the possibility that the results will not generalize to other sub-task orders (e.g., hardto-easy test situations). However, Deák and Narasimham (2013) also found a strong correlation between the FIM-An and FIM-Ob tests without this constraint. Nonetheless, order-specific between-test correlations should be evaluated in future studies. Finally, in future studies it would be ideal to obtain independent estimates of each child's comprehension of each cue or rule. Although adequate cue-comprehension estimates are almost never obtained in studies of children's EF or cognitive flexibility, they provide important information (Munakata \& Yerys, 2001). Fortunately, the correlation between FIM tests persisted when first-block accuracy (an index of cue comprehension) and vocabulary were partialled out, indicating that these were not determining factors. This result therefore confirm very limited cross-test consistency of flexibility in young children, particularly in cue-based induction of word meanings. 


\section{References}

Ackerman, P. L. (1988). Determinants of individual differences during skill acquisition: cognitive abilities and information processing. Journal of Experimental Psychology: General, 117(3), 288-318.

Allport, A., Styles, E.A., \& Hsieh, S. (1994). Shifting intentional set: Exploring the dynamic control of tasks. In C. Umiltà (Ed.), Attention and performance $X V$ (pp. 421-452). Cambridge, MA: MIT Press.

Baddeley, A., Chincotta, D., \& Adlam, A. (2001). Working memory and the control of action: Evidence from task switching. Journal of Experimental Psychology: General, 130, 641-657.

Barceló, F., \& Knight, R.T. (2002). Both random and perseverative errors underlie WCST deficits in prefrontal patients. Neuropsychologia, 40, 349-356.

Barkley, R. (2012). Executive Functions: What They Are, How They Work, and Why They Evolved. New York: Guilford.

Bilalić, M., McLeod, P., \& Gobet, F. (2008). Inflexibility of experts-Reality or myth? Quantifying the Einstellung effect in chess masters. Cognitive Psychology, 56(2), 73-102.

Blackwell, K.A., Cepeda, N.J., \& Munakata, Y. (2009). When simple things are meaningful: Working memory strength predicts children's cognitive flexibility. Journal of Experimental Child Psychology, 103, 241-249.

Blackwell, K.A., Chatham, C.H., Wiseheart, M., \& Munakata, Y. (2014). A developmental window into trade-offs in executive function: The case of task switching versus response inhibition in 6-year-olds. Neuropsychologia.

Blaye, A. \& Bonthoux, F. (2001). Thematic and taxonomic relations in preschoolers: the development of flexibility in categorization choices. British Journal of Developmental Psychology, 19(3), 395-412.

Blaye, A., Bernard-Peyron, V., Paour, J.L., \& Bonthoux, F. (2006). Categorical flexibility in children: Distinguishing response flexibility from conceptual flexibility; the protracted development of taxonomic representations. European Journal of Developmental Psychology, 3, 163-188.

Bohlmann, N.L., \& Fenson, L. (2005). The effects of feedback on perseverative errors in preschool aged children. Journal of Cognition and Development, 6, 119-131.

Bull, R., \& Scerif, G. (2001). Executive functioning as a predictor of children's mathematics ability: inhibition, switching, and working memory. Developmental Neuropsychology, 19, 273-293.

Burgess, P.W., Alderman, N., Forbes, C., et al. (2006). The case for the development and use of "ecologically valid" measures of executive function in experimental and clinical neuropsychology. Journal of the International Neuropsychological Society, 12, 194-209. 
Carlson, S.M. (2005). Developmentally sensitive measures of executive function in preschool children. Developmental Neuropsychology, 28(2), 595-616.

Carlson, S.M., Moses, L.J., \& Breton, C. (2002). How specific is the relation between executive function and theory of mind? Contributions of inhibitory control and working memory. Infant and Child Development, 11, 73-92.

Cartwright, K.B., Marshall, T.R., Dandy, K.L., \& Isaac, M.C. (2010). The development of graphophonological-semantic cognitive flexibility and its contribution to reading comprehension in beginning readers. Journal of Cognition and Development, 11(1), 61-85.

Cepeda, N. J., Blackwell, K. A., \& Munakata, Y. (2013). Speed isn’t everything: Complex processing speed measures mask individual differences and developmental changes in executive control.

Developmental Science, 16, 269-286.

Cepeda, N.J., Cepeda, M.L., \& Kramer, A.F. (2000). Task switching and attention deficit hyperactivity disorder. Journal of Abnormal Child Psychology, 28, 213-226.

Cepeda, N.J., Kramer, A.F., \& Gonzalez de Sather, J. C. (2001). Changes in executive control across the life-span: Examination of task switching performance. Developmental Psychology, 37, 715-730.

Cepeda, N.J., \& Munakata, Y. (2007). Why do children perseverate when they seem to know better: Graded working memory or directed inhibition? Psychonomic Bulletin and Review, 14, 1058-1065.

Centers for Disease Control. (2013, December). Births: Final data for 2012. National Vital Statistics Reports, 62(9). http://www.cdc.gov/nchs/data/nvsr/nvsr62/nvsr62_09.pdf.

Chen, Z. (1999). Schema induction in children's analogical problem solving. Journal of Educational Psychology, 91(4), 703-715.

Chelune, G.J., \& Baer, R.A. (1986). Developmental norms for the Wisconsin Card Sorting test. Journal of Clinical and Experimental Neuropsychology, 8(3), 219-228.

Chevalier, N., \& Blaye, A. (2008). Cognitive flexibility in preschoolers: The role of representation activation and maintenance. Developmental Science, 11, 339-353.

Das Gupta, P., \& Bryant, P.E. (1989). Young children's causal inferences. Child Development, 60(5), $1138-1146$

Davidson, M.C., Amso, D., Anderson, L.C., \& Diamond, A. (2006). Development of cognitive control and executive functions from 4 to 13 years: Evidence from manipulations of memory, inhibition, and task switching. Neuropsychologia, 44, 2037-2078.

Deák, G.O. (2000). The growth of flexible problem solving: Preschool children use changing verbal cues to infer multiple word meanings. Journal of Cognition and Development, 1, 157-191. 
Deák, G.O. (2003). The development of cognitive flexibility and language abilities. In R. Kail (Ed.), Advances in child development and behavior, Vol. 31 (pp. 271-327). San Diego: Academic Press.

Deák, G.O. (2006). Do children really confuse appearance and reality? TRENDS in Cognitive Sciences, $10,546-550$.

Deák, G.O., \& Boddupalli, G. (submitted) Flexible reasoning about object functions by young children.

Deák, G.O., \& Narasimham, G. (2003). Is perseveration caused by inhibition failure? Evidence from preschool inferences about word meanings. Journal of Experimental Child Psychology, 86, 194-222.

Deák, G.O., \& Narasimham, G. (2013). Young children's flexible use of semantic cues to word meanings: Converging evidence of individual and age differences. Journal of Child Language.

Deák, G.O., Ray, S.D., \& Brenneman, K. (2003). Children's perseverative appearance-reality errors are related to emerging language skills. Child Development, 74, 944-964.

Deák, G.O., Ray, S.D., \& Pick, A.D. (2004). Effects of age, reminders, and task difficulty on young children's rule-switching flexibility. Cognitive Development, 19, 385-400.

Dean, R.S., \& Woodcock, R.W. (1999). The WJ-R and Bateria-R in neuropsychological assessment: Research report number 3. Itasca, IL: Riverside Publishing Company.

Decker, S. L., Hill, S. K., \& Dean, R. S. (2007). Evidence of construct similarity in executive functions and fluid reasoning abilities. International Journal of Neuroscience, 117(6), 735-748.

Diamond, A., Kirkham, N., \& Amso, D. (2002). Conditions under which young children can hold two rules in mind and inhibit a prepotent response. Developmental Psychology, 38, 352-263.

Diamond, A., \& Taylor, C. (1996). Development of an aspect of executive control: Development of the abilities to remember what I said and to "Do as I say, not as I do." Developmental Psychobiology, 29, 315-334.

Dunn, L.M., \& Dunn, L.M. (1997). Peabody Picture Vocabulary Test-Third Edition. Circle Pines, MN: AGS Publishing.

Engle, R. W., \& Kane, M. J. (2004). Executive attention, working memory capacity, and a two-factor theory of cognitive control. Psychology of Learning and Motivation, 44, 145-200.

Eslinger, P.J., \& Grattan, L.M. (1993). Frontal lobe and frontal-striatal substrates for different forms of human cognitive flexibility. Neuropsychologia, 31, 17-28.

Frank, M. J., O'Reilly, R. C., \& Curran, T. (2006). When memory fails, intuition reigns Midazolam enhances implicit inference in humans. Psychological Science, 17(8), 700-707.

Friedman, N. P., Miyake, A., Young, S. E., DeFries, J. C., Corley, R. P., \& Hewitt, J. K. (2008). 
Individual differences in executive functions are almost entirely genetic in origin. Journal of Experimental Psychology: General, 137(2), 201-225.

Frye, D., Zelazo, P.D., \& Palfai, T. (1995). Theory of mind and rule-based reasoning. Cognitive Development, 10, 483-527.

Garon, N., Bryson, S. E., \& Smith, I. M. (2008). Executive function in preschoolers: a review using an integrative framework. Psychological Bulletin, 134(1), 31-60.

Gerstadt, C.L., Hong, Y.J., \& Diamond, A. (1994). The relationship between cognition and action: Performance of children 3 1/2-7 years old on a Stroop-like day-night test. Cognition, 53, 129-153.

Gruber, O., \& Goschke, T. (2004). Executive control emerging from dynamic interactions between brain systems mediating language, working memory and attentional processes. Acta Psychologica, 115, 105-121.

Hermer-Vazquez, L., Moffet, A., \& Munkholm, P. (2001). Language, space, and the development of cognitive flexibility in humans: The case of two spatial memory tasks. Cognition, 79, 263-299.

Holt, A.E. \& Deák, G.O. (2014). Children's task-switching: Missing our cue? Journal of Cognition and Development. 10.1080/15248372.2013.833921.

Horn, J. L., \& Cattell, R. B. (1966). Refinement and test of the theory of fluid and crystallized general intelligences. Journal of Educational Psychology, 57(5), 253.

Humphreys, L. G. (1979). The construct of general intelligence. Intelligence, 3(2), 105-120.

Ionescu, T. (2012). Exploring the nature of cognitive flexibility. New Ideas in Psychology, 30(2), 190-200.

Jacques, S., \& Zelazo, P.D. (2005). On the possible roots of cognitive flexibility. In B. Homer \& C. Tamis-LeMonda (Eds.), The development of social cognition and communication (pp. 53-81). Mahwah, NJ: Lawrence Erlbaum Associates.

Jurado, M. B., \& Rosselli, M. (2007). The elusive nature of executive functions: a review of our current understanding. Neuropsychology Review, 17(3), 213-233.

Kail, R. (1991). Processing speed declines exponentially during childhood and adolescence. Developmental Psychology, 27, 259-266.

Kail, R. \& Hall, L.K. (1994). Processing speed, naming speed, and reading. Developmental Psychology, 30, 949-954.

Kane, M. J., \& Engle, R. W. (2002). The role of prefrontal cortex in working-memory capacity, executive attention, and general fluid intelligence: An individual-differences perspective. Psychonomic Bulletin and Review, 9(4), 637-671. 
Kim, C., Johnson, N.F., Cilles, S.E., \& Gold, B.T. (2011). Common and distinct mechanisms of cognitive flexibility in prefrontal cortex. The Journal of Neuroscience, 31(13), 4771-4779.

Klahr, D., \& Chen, Z. (2003). Overcoming the positive-capture strategy in young children: Learning about indeterminacy. Child Development, 74(5), 1275-1296.

Kloo, D., \& Perner, J. (2005). Disentangling dimensions in the dimensional change card-sorting task. Developmental Science, 8, 44-56.

Knuth, E.J., Alibali, M.W., McNeil, N.M., Weinberg, A., \& Stephens, A.C. (2011). Middle school students' understanding of core algebraic concepts: Equivalence \& variable. In Early Algebraization (pp. 259-276). Springer Berlin Heidelberg.

Kramer, A.F., Cepeda, N.J., \& Cepeda, M.L. (2001). Methylphenidate effects on task-switching performance in attention-deficit/hyperactivity disorder. Journal of the American Academy of Child and Adolescent Psychiatry, 40, 1277-1284.

Krems, J.F. (1995). Cognitive flexibility and complex problem solving. In P. Frensch \& J. Funke (Eds.), Complex problem solving: The European perspective (pp. 201-218). Hillsdale, NJ: Erlbaum.

Li, S. Lindenberger, U., Hommel, B., Aschersleben, G., Prinz, W. \& Baltes, P.B. (2004). Transformations in the couplings among intellectual abilities and constituent cognitive processes across the life span. Psychological Science, 15, 155-163.

Luria, A.R. (1966). Higher cortical functions in man (B. Haigh, Trans.). New York: Basic Books. (Original work published 1962)

Luwel, K., Verschaffel, L., Onghena, P., \& De Corte, E. (2003). Strategic aspects of numerosity judgment: The effect of task characteristics. Experimental Psycholog, 50(1), 63-75.

Martin, M.M., \& Rubin, R.B. (1995). A new measure of cognitive flexibility. Psychological Reports, 76, 623-626.

Meiran, N., Chorev, N., \& Sapir, A. (2000) Component processes in task switching. Cognitive Psychology 41, 211-253

Miyake, A., Friedman, N. P., Emerson, M. J., Witzki, A.H., Howerter, A., \& Wager, T.D. (2000). The unity and diversity of executive functions and their contributions to complex "frontal lobe" tasks: A latent variable analysis. Cognitive Psychology, 41, 49-100.

Monsell, S., Yeung, N., \& Azuma, R. (2000). Reconfiguration of task-set: Is it easier to switch to the weaker task? Psychological Research, 63, 250-264.

Montgomery, D.E., \& Koeltzow, T.E. (2010). A review of the day-night task: The Stroop paradigm and interference control in young children. Developmental Review, 30(3), 308-330. 
Munakata, Y., \& Yerys, B. E. (2001). All together now: When dissociations between knowledge and action disappear. Psychological Science, 12(4), 335-337.

Narasimham, G., Deák, G.O., \& Wiseheart, M. (submitted). Measuring age and individual variability in rule-switching flexibility: The three dimension changes card sorting test (3DCCS).

Nguyen, S.P., \& Murphy, G.L. (2003). An apple is more than just a fruit: Cross-classification in children's concepts. Child Development, 74(6), 1783-1806.

O'Reilly, R., \& Frank, M. (2006). Making working memory work: a computational model of learning in the prefrontal cortex and basal ganglia. Neural Computation, 18(2), 283-328.

Perner, J., \& Lang, B. (2002). What causes 3-year-olds' difficulty on the Dimensional Change Card Sorting task? Infant and Child Development, 11, 93-105.

Postle, B. R., Berger, J. S., \& D’Esposito, M. (1999). Functional neuroanatomical double dissociation of mnemonic and executive control processes contributing to working memory performance. Proceedings of the National Academy of Sciences, 96(22), 12959-12964.

Ramscar, M., Dye, M., Gustafson, J.W., \& Klein, J. (2013). Dual routes to cognitive flexibility: Learning and response-conflict resolution in the Dimensional Change Card Sort Task. Child Development, 84(4), 1308-1323.

Ravizza, S. M., \& Carter, C.S. (2008). Shifting set about task switching: Behavioral and neural evidence for distinct forms of cognitive flexibility. Neuropsychologia, 46(12), 2924-2935.

Reimers, S., \& Maylor, E.A. (2005). Task switching across the life span: Effects of age on general and specific switch costs. Developmental Psychology, 41, 661-671.

Salthouse, T. A. (1994). The nature of the influence of speed on adult age differences in cognition. Developmental Psychology, 30(2), 240-259.

Salthouse, T.A., Fristoe, N., McGuthry, K.E., \& Hambrick, D.Z. (1998). Relation of task switching to speed, age, and fluid intelligence. Psychology and Aging, 13, 445-461.

Sattler, J. M. (2002). Assessment of children $\left(4^{\text {th }} E d\right)$. La Mesa, CA: Sattler.

Schneider, D.W., \& Logan, G.D. (2009). Selecting a response in task switching: Testing a model of compound cue retrieval. Journal of Experimental Psychology: Learning, Memory, \& Cognition, 35, 122136.

Simpson, A., \& Riggs, K.J. (2005). Factors responsible for performance on the day-night task: response set or semantics? Developmental Science, 8, 360-371.

Smith, S.M., \& Blankenship, S.E. (1991). Incubation and the persistence of fixation in problem solving. The American Journal of Psychology, 104, 61-87. 
Thompson-Schill, S., Ramscar, M. \& Evangelia, C. (2009). Cognition without control: When a little frontal lobe goes a long way. Current Directions in Psychological Science, 8, 259-263.

Woodcock, R.W., \& Johnson, M.B. (1989). Woodcock-Johnson Psychoeducational Battery Revised. Allen, TX: DLM Teaching Resources.

Wylie, G., \& Allport, A. (2000). Task switching and the measurement of "switch costs". Psychological Research, 63, 212-233.

Yeung, N., \& Monsell, S. (2003). Switching between tasks of unequal familiarity: The role of stimulus-attribute and response-set selection. Journal of Experimental Psychology: Human Perception and Performance, 29, 455-469.

Zelazo, P.D. (2006). The dimensional change card sort (DCCS): A method of assessing executive function in children. Nature Protocols, 1, 297-301.

Zelazo, P.D., \& Frye, D. (1998). Cognitive complexity and control: II. The development of executive function in childhood. Current Directions in Psychological Science, 7, 121-126.

Zelazo, P.D., Frye, D., \& Rapus, T. (1996). An age-related dissociation between knowing rules and using them. Cognitive Development, 11, 37-63.

Zelazo, P. D., Müller, U., Frye, D., \& Marcovitch, S. (2003). The development of executive function in early childhood. Monographs of the Society for Research in Child Development, 68(3), 1-151. 


\section{Author Note}

Gedeon O. Deák: Department of Cognitive Science, University of California, San Diego. Melody Wiseheart: Department of Psychology and LaMarsh Centre for Child and Youth Research, York University. This work was supported by grant from the National Science Foundation (NSF-BCS0902027) and from the UCSD Academic Senate to G. Deák. Thanks to Elaine Blank, Sean Marco, Ali Moeller, Sam Sedlik, Mieke VanderBourght, Cherry Vu, and Rachel Weisser for assistance in data collection and coding. Thanks to Gabriel Catalano and Annelise d'Souza for helpful comments on earlier drafts. Special thanks to all of the children who participated. Address correspondences to gdeak@ucsd.edu. 
Appendix

A. Test Order in Main Sample and Replication Sample. Note that number of tests is not matched across days because the tests varied widely in duration (e.g., from 1-3 min per indeterminacy detection test, to over $20 \mathrm{~min}$ for the FIM-Ob test). ID = Indeterminacy Detection.

\begin{tabular}{|c|c|c|c|}
\hline \multirow{4}{*}{ Main Sample } & Session 1 & Session 2 & Session 3 \\
\cline { 2 - 4 } & [Matching game] & Luria Tapping & Box Completion \\
\cline { 2 - 4 } & 3DCCS & FIM-Ob & Stroop Day/Night \\
\cline { 2 - 4 } & [Flexible Tool-Use Test] & PPVT-3 & FIM-An \\
\cline { 2 - 4 } & ID (Contents 1) & ID (Words) & ID (Object 1, then Color) \\
\cline { 2 - 4 } & & Memory for Names & Causal Reasoning \\
\cline { 2 - 4 } & & ID (Contents 2) & ID (Object 2) \\
\hline
\end{tabular}

\begin{tabular}{|c|c|c|c|}
\hline \multirow{4}{*}{$\begin{array}{c}\text { Replication } \\
\text { Sample }\end{array}$} & Stroop Day/Night & Memory for Names & Luria Tapping \\
\cline { 2 - 4 } & PPVT-3 & [Flexible Tool-Use Test] & FIM-Ob \\
\cline { 2 - 4 } & Box Completion & ID (Object 2) & [Matching game] \\
\cline { 2 - 4 } & ID (Color) & Causal Reasoning & ID (Words) \\
\cline { 2 - 4 } & FIM-An & & 3DCCS \\
\hline
\end{tabular}


B. Key instructions in the cognitive flexibility tests.

\begin{tabular}{|c|c|}
\hline Test & Instruction \\
\hline $\begin{array}{l}F I M-O b \\
\text { Initial } \\
\text { Instruction }\end{array}$ & $\begin{array}{l}\text { "First look at this one. (E is holding standard up for child to see) Let me tell you something about } \\
\text { it. This one is made of [WORD } \mathrm{WOR}_{1} \text {. See, it's made of [WORD } \mathrm{WO}_{1} \text {. Now look at these." (second } \\
\text { experimenter hands first experimenter the first box of objects with the lid already removed). } \\
\left.\text { "Can you find me another one that is made of [WORD }{ }_{1}\right] \text { just like this one? (hold up standard } \\
\text { when you say 'just like this one' and keep it held above the comparison objects) }\end{array}$ \\
\hline $\begin{array}{l}\text { Switch } \\
\text { Instruction } \\
\text { (example) }\end{array}$ & $\begin{array}{l}\text { "Now I am going to show you these things again, but I am going to tell you something new about } \\
\text { them. Remember this one? [Touching Standard] Let me tell you something new about it. This } \\
\text { one is shaped like a(n) }\left[\mathrm{WORD}_{2}\right] \text {. See, it's shaped like a(n) }\left[\mathrm{WORD}_{2}\right] \text {. Now look at these. } \\
\text { [Presenting comparison objects.] Can you find me another one that is shaped like a(n) }\left[\mathrm{WORD}_{2}\right] \\
\text { just like this one?" }\end{array}$ \\
\hline $\begin{array}{l}\text { FIM-An } \\
\text { Initial } \\
\text { Instruction }\end{array}$ & $\begin{array}{l}\text { "Now we are going to play a game with some cool pictures of space creatures. I am going to } \\
\text { show you some pictures and then I am going to tell you something about them. Let's try it! } \\
\text { [Placing Standard picture] See this one? This one is a [WORD }] \text {. See, he is a [WORD } 1 \text {. Now let } \\
\text { me show you some more pictures. [Placing comparison pictures.] Can you find me another one } \\
\text { that is a }\left[\mathrm{WORD}_{1}\right] \text { just like this one?" }\end{array}$ \\
\hline $\begin{array}{l}\text { Switch } \\
\text { Instruction } \\
\text { (example) }\end{array}$ & $\begin{array}{l}\text { "Now I am going to tell you something new about these creatures. Are you ready? Look at this } \\
\text { one [Placing Standard] Remember this one? This one is holding a }\left[\mathrm{WORD}_{2}\right] \text {. See, he is holding a } \\
{\left[\mathrm{WORD}_{2}\right] \text {. Now look at these. [Placing comparison pictures.] Can you find me another one that }} \\
\text { is holding a }\left[\mathrm{WORD}_{2}\right] \text { just like this one? }\end{array}$ \\
\hline $\begin{array}{l}3 D C C S \\
\text { Initial } \\
\text { Instruction }\end{array}$ & $\begin{array}{l}\text { "Now we are going to play the animal game. Let me tell you how to play the animal game. In } \\
\text { the animal game, all dogs go in here, all fish go in here, and all birds go in here. [Pointing] So do } \\
\text { you see this picture of a dog here? That's to remind you that all dogs go in here. And do you see } \\
\text { this picture of a fish... [etc.]. ... So all dogs go in here, all fish go in here, and all birds go in here. } \\
\text { Are you ready to play the animal game?" }\end{array}$ \\
\hline $\begin{array}{l}\text { Switch } \\
\text { Instruction } \\
\text { (example) }\end{array}$ & $\begin{array}{l}\text { "Are you ready to play a new game? We're going to play the color game. Let me tell you how to } \\
\text { play the color game. In the color game all blue things go in here, all red things go in here, and.... } \\
\text { [Pointing] So do you see this blue thing here? That's to remind you that all blue things go in } \\
\text { here. Do you see this red thing... [etc.]? .... So, all blue things go in here, all red things go here, } \\
\text { and all yellow things go here. Are you ready to play the color game? }\end{array}$ \\
\hline
\end{tabular}


C. Items in Causal Inference test (based on Das Gupta \& Bryant, 1989).

\begin{tabular}{|c|l|}
\hline Pre $\rightarrow$ Post Event Photographs & \multicolumn{1}{c|}{ Choices } \\
\hline \multicolumn{2}{|c|}{ Practice Problems } \\
\hline tomato $\rightarrow$ sliced tomato & WHISK, SPATULA, MEASURING CUPS, KNIFE \\
\hline torn shirt $\rightarrow$ sewn shirt & TEAPOT, ROLLERSKATE, MUG, NEEDLE/THREAD \\
\hline \multicolumn{2}{|c|}{ Test Problems: Easier } \\
\hline spilled dirt $\rightarrow$ swept dirt & CHAIR, TISSUE, CLOCK, BROOM \\
\hline raw egg $\rightarrow$ cooked egg & BLENDER, DRYING RACK, NAPKIN HOLDER, STOVE \\
\hline messy hair $\rightarrow$ brushed hair & SPONGE, TOOTHBRUSH, ROLLING PIN, HAIRBRUSH \\
\hline torn paper $\rightarrow$ taped paper & KEYS, TOY BLOCKS, CRAYONS, TAPE \\
\hline & Test Problems: Harder \\
\hline wet plate $\rightarrow$ dry plate & SINK, MICROWAVE, CALCULATOR, TOWEL \\
\hline chalkboard w/ writing $\rightarrow$ erased board & CHALK, SCISSORS, STAPLER, ERASER \\
\hline broken flowerpot $\rightarrow$ fixed pot & HAMMER, LIGHT BULB, PAINT BRUSH, GLUE \\
\hline dirty shirt $\rightarrow$ clean shirt & KETCHUP, PURSE, IRON, DETERGENT \\
\hline
\end{tabular}


D. Cross-tabulation of individual response patterns in the FIM-Ob, FIM-An, and 3DCCS.

\begin{tabular}{|l|c|c|c|c|c|}
\hline FIM-Ob & Flexible & $\begin{array}{c}\text { Partly } \\
\text { Flexible }\end{array}$ & Indiscriminate & Perseverative & Totals \\
\hline Flexible & $\mathbf{1 9}$ & 2 & 0 & 0 & 21 \\
\hline Partly Flexible & 12 & $\mathbf{1}$ & 1 & 2 & 16 \\
\hline Indiscriminate & 9 & 6 & $\mathbf{1 2}$ & 8 & 35 \\
\hline Perseverative & 0 & 4 & 5 & $\mathbf{1 4}$ & 23 \\
\hline \multicolumn{1}{|c|}{ Totals } & 40 & 13 & 18 & 24 & [46 of] 95 \\
\hline
\end{tabular}

\begin{tabular}{|l|c|c|c|c|c|}
\hline FIM-Ob & Flexible & $\begin{array}{c}\text { Partly } \\
\text { Flexible }\end{array}$ & Indiscriminate & Perseverative & Totals \\
\hline Flexible & $\mathbf{1 5}$ & 4 & 0 & 2 & 21 \\
\hline Partly Flexible & 12 & $\mathbf{2}$ & 1 & 1 & 16 \\
\hline Indiscriminate & 8 & 4 & $\mathbf{5}$ & 18 & 35 \\
\hline Perseverative & 8 & 2 & 6 & $\mathbf{7}$ & 23 \\
\hline Totals & 43 & 12 & 12 & 28 & [29 of] 95 \\
\hline
\end{tabular}

\begin{tabular}{|l|c|c|c|c|c|}
\hline 3DCCS & FlM-An & $\begin{array}{c}\text { Partly } \\
\text { Flexible }\end{array}$ & Indiscriminate & Perseverative & Totals \\
\hline Flexible & $\mathbf{2 3}$ & 6 & 5 & 9 & 43 \\
\hline Partly Flexible & 8 & $\mathbf{3}$ & 0 & 1 & 12 \\
\hline Indiscriminate & 2 & 1 & $\mathbf{3}$ & 6 & 12 \\
\hline Perseverative & 7 & 3 & 10 & $\mathbf{8}$ & 28 \\
\hline \multicolumn{1}{|c|}{ Totals } & 40 & 13 & 18 & 24 & [37 of] 95 \\
\hline
\end{tabular}

